\title{
Capacidades do Estado brasileiro e arquitetura institucional da EaD: da organização burocrática à autonomia inserida dos órgãos estatais
}

\author{
Brazilian State Capacities and DE institutional architecture: from bureaucratic \\ organization to inserted autonomy by state organs \\ Capacidades del Estado brasileño y arquitectura institucional de la EaD: de la \\ organización burocrática a la autonomía insertada de los órganos estatales
}

DANIELA DA COSTA BRITTO PEREIRA LIMA MÔNICA DESIDERIO

\begin{abstract}
Resumo: O tema deste estudo é a arquitetura institucional da educação a distância $(\mathrm{EaD})$ no Brasil sob a ótica das capacidades do Estado no que se refere à organização burocrática. Seu objetivo geral é apresentar e discutir algumas das capacidades do Estado brasileiro para gerir sua política pública de EaD. A pesquisa é do tipo bibliográfica e de natureza empírica, com suporte teórico em Evans (1993, 1995, 2004). O estudo empírico considerou o mapeamento e a análise da arquitetura institucional da EaD no Brasil entre 2010 e 2013 (LIMA, 2013). Constata-se que o Estado precisa rever sua arquitetura institucional da EaD, visando desenvolver a sua capacidade de organização burocrática e autonomia inserida, para passar de um Estado intermediário para desenvolvimentista.
\end{abstract}

Palavras-chave: Educação a distância; educação superior; capacidades do Estado; arquitetura institucional.

\begin{abstract}
The theme of this study is the institutional architecture of distance education - EaD - in Brazil, from the point of view of the state's capabilities, regarding the bureaucratic organization. Its general objective is to present and discuss some of the capabilities of the Brazilian State to manage it's public DE policy. The research is a bibliographical and empirical study, with theoretical support in Evans (1993, 1995, 2004). The empirical study considered the mapping and analysis of the institutional architecture of $\mathrm{EaD}$ in Brazil between 2010 and 2013 (LIMA, 2013). It concludes that the Brazilian State needs to reassess its DE institutional architecture as a means to develop its bureaucratic organization capacity and inserted autonomy, and as a condition to move from an intermediary State to a developed one.
\end{abstract}

Keywords: distance education; higher education; State capacity; institutional architecture.

Resumen: El tema de este estudio es la arquitectura institucional de la educación a distancia (EaD) en Brasil bajo la óptica de las capacidades del Estado en lo que se refiere a la organización burocrática. Su objetivo general es presentar y discutir algunas de las capacidades del Estado brasileño para gestionar su política pública de EaD. La investigación es del tipo bibliográfica y de naturaleza empírica, con 
soporte teórico en Evans (1993, 1995, 2004). El estudio empírico consideró el mapeo y el análisis de la arquitectura institucional de EaD en Brasil entre 2010 y 2013 (LIMA, 2013). Se constata que el Estado necesita revisar su arquitectura institucional de la EaD, buscando desarrollar su capacidad de organización burocrática y autonomía insertada, para pasar de un Estado intermedio para desarrollista.

Palabras clave: Educación a distancia; educación universitaria; capacidades del Estado; arquitectura institucional.

\section{INTRODUÇÃO}

Os atores da burocracia estatal, conforme a abordagem institucionalista, propõem e desenvolvem ações como produto das interações internas e externas com outros atores individuais ou coletivos da sociedade organizada e do próprio Estado, e, ao fazê-lo, desenvolvem distintas capacidades. Evans (1995; 2004) defende o pressuposto de que não é a prevalência da burocracia que prejudica o desenvolvimento das capacidades do Estado, mas a sua insuficiência.

Isso traz como desafio a construção de um modelo baseado no equilíbrio entre insulamento e inserção social (o que chama de autonomia inserida) associado a uma burocracia meritocrática (autônoma), com incentivos de progressão e relações externas conectadas à sociedade civil (COSTA; NEVES, 2013).

Este artigo, com base nas contribuições de Evans (1993; 1995; 2004), visa a discutir a capacidade de organização burocrática do Estado brasileiro de gerir sua política pública de Educação a Distância $(\mathrm{EaD})$, a partir do mapeamento e análise da arquitetura institucional entre 2010 e 2013 (LIMA, 2013). Fundamenta-se em pesquisa bibliográfica, documental, e entrevistas com os gestores de alto escalão dos órgãos centrais de acompanhamento, regulação e avaliação das ações de $\mathrm{EaD}$ (CAPES, SERES/MEC, SEB/MEC e INEP) ${ }^{1}$ e com os atores pertencentes aos órgãos colegiados da área (Fórum de Coordenadores UAB e CONAES) ${ }^{2}$. A escolha dos órgãos e sujeitos da pesquisa deveu-se a sua relevância no processo de constituição dessa modalidade de ensino no país à época da coleta de dados.

Neste estudo, consideramos arquitetura institucional tanto a estrutura e organização segundo as regras formais (consolidadas em documentos legais) de determinados órgãos quanto a percepção dos atores que neles atuam. As rotinas e

1 Respectivamente: Coordenação de Aperfeiçoamento de Pessoal de Nível Superior, Secretaria de Regulação e Supervisão da Educação Superior, Secretaria de Educação Básica e Instituto Nacional e Estudos e Pesquisas Educacionais.

2 UAB - Sistema Universidade Aberta do Brasil; CONAES - Comissão Nacional de Avaliação da Educação Superior. 
crenças são elementos cuja identificação completa a análise realizada e contribuem para desvelar aspectos não explicitados nas regras formais.

A educação a distância $(\mathrm{EaD})$ é uma modalidade de educação em franco crescimento desde sua regulamentação realizada pela $\operatorname{LDB} n^{\circ}$ 9. 394/1996. Entre 2002 e 2016, o número de matrículas no ensino superior saltou de 40.714 (INEP, 2002) para 1.494.418 (INEP, 2016), apresentando aumento de 3.570\%, e inversão da expansão entre as IES públicas e privadas, conforme tabela 1.

\section{Tabela 1 - Número de matrículas EaD por categoria administrativa}

\begin{tabular}{|c|c|c|c|}
\hline \multicolumn{2}{|c|}{ IES Públicas } & \multicolumn{2}{c|}{ IES Privadas } \\
\hline Ano & Matrículas & Ano & Matrículas \\
\hline 2002 & 34.322 & 2002 & 6.392 \\
\hline 2016 & 122.601 & 2016 & 1.371 .817 \\
\hline
\end{tabular}

Fonte: Censo da Educação Superior (INEP, 2002 e 2016)

Esse crescimento e a inversão da expansão justificam a pesquisa acerca de como o Estado organiza sua arquitetura institucional, já que o sucesso ou o fracasso dos projetos transformadores depende de como se harmonizam com as estratégias dos campos específicos (EVANS, 2004).

Não se pretende fazer neste estudo uma avaliação da política pública de EaD no Brasil e, sim, uma análise da capacidade do Estado a partir de sua arquitetura institucional de gestão da EaD. O artigo está dividido em três seções: abordagem teórica sobre as capacidades estatais utilizadas, apresentação dos dados acerca da capacidade burocrática e dos indícios de mecanismos de autonomia inserida dos órgãos estatais que atuam ou deveriam atuar na $\mathrm{EaD}$ e, por fim, a análise da capacidade burocrática por meio dos planos de carreira e capacitação dos gestores de alto escalão.

\section{CAPACIDADES DO ESTADO: ORGANIZAÇÃO BUROCRÁTICA E AUTONOMIA INSERIDA}

A abordagem teórica de capacidades do Estado propõe uma reflexão a partir da multiplicidade de resultados encontrados nos processos de reformas de países em diferentes condições de desenvolvimento e argumenta que o sucesso das ações do Estado não depende só de seu modelo, mas, também, de sua capacidade de implementar políticas públicas e sustentar compromissos.

Segundo Grindle (1996), a capacidade do Estado para formular e implementar políticas públicas refere-se a sua capacidade de responder às 
demandas sociais, para permitir que os canais que representem os interesses da sociedade incorporem a participação da sociedade como um todo (e não só da parcela detentora do capital) na tomada de decisões e resolução de conflitos.

Compreender o Estado como desenvolvedor de capacidade de expansão exige perceber o sentido de autonomia inserida de Evans (1995), em que a burocracia é vista numa perspectiva institucional que avança em relação ao modelo weberiano de racionalidade ao compreender que a capacidade do Estado depende do equilíbrio entre o grau de insulamento burocrático e de inserção nas relações societárias (COSTA, 2011).

Para Evans (2004), a autonomia inserida trata de uma combinação de autonomia e parceria em que o Estado deve possuir autonomia relativa da classe dominante para promover o desenvolvimento, formular e implementar objetivos coletivos. Esta ação depende da combinação das características da máquina pública e carreiras burocráticas com a capacidade do Estado para gerir as relações sociais.

Há ênfase na incorporação dos interesses coletivos de forma que haja conexão com as diversas redes externas, considerando o grau de profissionalização da burocracia (processo de seleção meritocrática e mecanismos internos de promoção dos funcionários públicos) e a capacidade de se inserir o projeto governamental para atender às necessidades da sociedade. Estados ineficientes não contam com normas burocráticas e padrões previsíveis no aparato estatal e a fragilidade da estrutura burocrática abre precedência para o privilégio de interesses particularistas (EVANS, 1995; COSTA, 2011).

Ao observar a atuação do Estado, Evans (1993; 2004) construiu tipologias que caracterizam sua conduta na economia e no desenvolvimento: Estado predador, Estado intermediário e Estado desenvolvimentista.

O Estado predador promove o desenvolvimento às custas da sociedade, $\mathrm{e}$ a preocupação da classe política com a busca de renda converte a sociedade em sua presa. Observa-se a ausência de uma burocracia weberiana. É um Estado arbitrário e desorganizador da sociedade civil e, geralmente, conduzido por um líder forte que atua dentro de uma tradição patrimonialista. Já o Estado desenvolvimentista se organiza internamente como burocracia weberiana mediante recrutamento por mérito; é altamente seletivo, utiliza compensações ao longo de carreiras de longo prazo - cria compromisso, coerência corporativa e autonomia, sem isolamento da sociedade. Supõe um Estado meritocrático e, ao mesmo tempo, inserido no ambiente societário.

Por fim, no Estado intermediário, a burocracia apresenta parcialmente as características de uma burocracia weberiana. Evans (2004) apresenta o Brasil como Estado intermediário, porque não há uma verdadeira meritocracia e, ainda que em 
alguns setores e agências exista o predomínio do profissionalismo, em outros a autoridade ocorre por meio de laços pessoais e pela corrupção. Há dificuldade na institucionalização de procedimentos de recrutamento meritocrático, as carreiras não são de longo prazo, dependendo, na maioria das vezes, de mudança na liderança política levando à ausência de compromisso de longo prazo entre os gestores de alto escalão com os órgãos em que atuam. A autonomia inserida é um atributo mais parcial que global.

A transição de Estado intermediário para desenvolvimentista pressupõe pensar sobre como promover a autonomia e a parceria considerando as características históricas e idiossincráticas que particularizam cada sociedade.

Para compreender a capacidade do Estado manifesta na EaD no Brasil, analisamos o grau de organização burocrática dos órgãos governamentais e, ao mesmo tempo, observamos como estes criam mecanismos de cooperação e parceria para que possam desenvolver uma relação de atendimento às reais necessidades e possibilidades da área e do público atingido, considerando também a tipologia proposta por Evans explicitada acima.

\section{CAPACIDADE BUROCRÁTICA E INDÍCIOS DE MECANISMOS DE AUTONOMIA INSERIDA DOS ÓRGÃOS E SEUS ATORES}

Antes de apresentar os dados coletados, é necessário resgatar o universo da pesquisa, definido a partir das características da EaD na Educação Superior no Brasil entre 2010 e 2013, composto pelos órgãos de atuação na Educação Superior e que, então, atuavam diretamente com a EaD. Os atores/sujeitos definidos seguiram o critério da função ocupada, ou seja, os gestores de alto escalão em cargos que possuíam como função fazer gestão, acompanhamento e avaliação da Educação Superior e a distância.

Os órgãos pesquisados foram Capes, Inep, Conaes, Fórum de Coordenadores UAB e MEC (SERES, SESU ${ }^{3}$ e SEB). Dentre os selecionados, apenas a SESU não se disponibilizou a participar da pesquisa, considerando que a EaD não possuía relação com essa Secretaria (LIMA, 2013). Este fato já foi o primeiro indício de falta de organização entre os órgãos do Estado brasileiro, pois se a Capes fazia a gestão da EaD pública no país, fica o questionamento acerca de a que órgão caberia a gestão da $\mathrm{EaD}$ privada.

Para resguardar a identidade dos entrevistados, utilizou-se a sigla do órgão de que faziam ou fizeram parte, seguida de uma letra do alfabeto. 
As características burocráticas dos órgãos pesquisados e sua arquitetura institucional foram identificadas com relação a: aspectos legais, estrutura hierárquica/processo de seleção, formação dos gestores, atividade-fim e os indícios de autonomia inserida, para, posteriormente, analisar a qualificação oferecida pelos órgãos (que afetam sua profissionalização) e plano de carreira dos funcionários.

Convém destacar que, dentre os órgãos pesquisados ${ }^{4}$, no período da pesquisa quando se finaliza este artigo, apenas a CAPES possui uma Diretoria voltada especificamente para a EaD e o MEC, por meio da SERES, que possuía e ainda possui duas Coordenações gerais voltadas para a EaD.

A Capes atua na EaD por meio da Diretoria de Educação a Distância (DED). Em 2008, a DED possuía quatro coordenações e em 2012 passou a ter três, com a manutenção da Coordenação-geral de Supervisão e Fomento; alterou a Coordenação de articulação acadêmica para de Programas e Cursos em ensino a distância; fez a junção da Coordenação geral de infraestrutura de polos e núcleos com a de política de tecnologia de informação, passando a ser denominada Coordenação de inovação em ensino a distância.

Ao se observarem as atribuições da DED no decreto ${ }^{\circ} 7692 / 2012$ (BRASIL, 2012), nota-se que estão todas voltadas para a coordenação e o fomento de cursos a distância do Sistema UAB ou para a formação inicial e continuada de professores. Ao se priorizar apenas a UAB (Sistema público de oferta), deixa-se um hiato acerca de uma política clara de EaD para a educação superior privada. Com relação à caracterização dos gestores, dentre os quatro havia: dois comissionados, um requisitado de uma IES e um Gestor Público; o tempo no cargo era de um ano e meio para todos; a formação, dividida em: Engenharia Civil, Administração, Letras e Matemática. Com relação à formação em EaD: dois não a possuíam, um tinha $\mathrm{PhD}$ em EaD e outro fez cursos modulares em EaD; todos apresentavam larga experiência anterior com EaD.

$\mathrm{Na} \mathrm{DED} / \mathrm{CAPES}$, passaram duas gestões até a época em que foi feita a pesquisa de campo. O primeiro diretor ficou três anos e meio no cargo, e o segundo diretor e sua equipe, no final de 2012, lá estavam havia um ano e meio.

Uma característica da arquitetura institucional da EaD na CAPES, que é mantida ainda hoje, é o Fórum de Coordenadores $\mathrm{UAB}^{5}$, como meio de escuta e diálogo com a comunidade, através de um canal institucionalizado para a definição 
de metas, estratégias e políticas para a área, podendo ser considerado mecanismo de autonomia inserida. Entretanto, seu grau de institucionalização parece-nos fator crítico para sua manutenção.

O Fórum é composto por todos os Coordenadores UAB e adjuntos das IES públicas que aderiram ao Sistema, sendo que o presidente e o vice-presidente devem ser eleitos por seus membros. A figura do Coordenador UAB aparece na Resolução CD/FNDE no 26, de 05 de junho de 2009. Para ocupar o cargo e receber bolsa pesquisa correspondente, não é necessário ter formação ou experiência em EaD, o que compromete suas ações (LIMA, 2013). Porém, com relação a seu papel:

[...] é muito complexo. Ele tem de gerir todo o processo desde a sua criação, acompanhar seu desenvolvimento e implantação, e avaliar as ações tomadas para a negociação com os órgãos de fomento. Envolve, portanto, conhecimento administrativo, acadêmico, científico, burocrático, político e de gestão de pessoas. Sópor este último, a complexidade se intensifica, pois a quantidade de pessoas que atua na EaD, nas diferentes funções, acaba por ser de responsabilidade também da coordenação UAB. [...] Graças ao Fórum temos uma organização interna dos Coordenadores que não necessariamente depende da CAPES. Somos legitimados por ela, mas nosso trabalho ultrapassa o que fazemos junto à DED-CAPES (Entrevistado FÓRUM B, 2012).

Esse posicionamento se refere às atividades coletivas que ocorrem em forma de Grupos de Trabalho (GT), tanto presenciais, quanto virtualmente por meio do Ambiente Virtual de Trabalho da UAB (ATUAB), "além do Fórum de área dos Coordenadores de curso das licenciaturas e da administração pública (PNAP)" (Entrevistado CAPES F, 2012).

O Fórum de Coordenadores UAB, além dos encontros previstos, emite Cartas para a DED/CAPES com as considerações e condições discutidas acerca dos assuntos pertinentes à condução do Sistema UAB nas IES, além da discriminação de impactos e proposições. Na Carta de Belo Horizonte, do dia 06 de junho de 2012, é explicitado que a presidência do Fórum busca fazer articulações com entidades e associações representativas, o que condiz com a caracterização das redes externas defendidas por Evans (2004), na relação do Estado para a busca das tomadas de decisão.

$\mathrm{Na}$ estrutura regimental da SERES/MEC, ainda existia, em 2012, uma divisão nas coordenações-gerais de cursos presenciais e a distância, mas, na prática, após a realização das entrevistas, verificou-se que o que estava efetivado era a divisão das coordenações de supervisão no ensino superior abarcando as duas modalidades com base na natureza da demanda: se ordinária (denúncia, publicidade ou solicitação) ou especial (a partir dos índices).

O gestor que ocupava a Coordenação-geral era graduado em Direito, com mestrado em Administração Pública. Não fazia parte do quadro efetivo do 
MEC e foi disponibilizado da sua vinculação de origem ao Ministério Público, tendo ocupado cargo na supervisão por menos de um ano. $\mathrm{O}$ gestor não havia tido experiência anterior na área de $\mathrm{EaD}$.

O gestor da SEB/MEC foi entrevistado pela relação que o seu trabalho possuía com a Rede Nacional de Formação de Professores, sendo citado por diversas vezes na entrevista realizada ao Entrevistado Fórum A (2012), ao expressar a dificuldade de lidar com o Fórum Permanente Estadual (e essa Rede trabalhava em função das demandas do Fórum) e na medida em que a sua Coordenaçãogeral estava vinculada à formação continuada de professores. Essa Coordenação é um exemplo dos rearranjos que são constantemente realizados no organograma do Ministério da Educação, que, ao que parece, conforme mudanças havidas na SERES, extinção da SEED e outras, têm sido constantes.

Eu sou coordenador. A coordenação não tem nome. Eu sou coordenador de formação continuada, mas essa coordenação no organograma do Ministério não tem nome. Informalmente a chamamos de coordenação de formação continuada. [...]Ela é vinculada à Diretoria de apoio à gestão educacional, dentro da SEB. (Entrevistado MEC C, 2012).

Sua formação era em Relações Internacionais, estava no cargo à época da entrevista há um ano, não era funcionário do MEC, mas do Ministério do Planejamento em exercício descentralizado no Ministério da Educação.

Assim, semelhante ao que identificamos na DED/CAPES, SERES, também no MEC os gestores não eram efetivos dos órgãos em que atuavam, apresentando um tempo inferior a cinco anos, apontando para a necessidade de atenção aos cargos de alto escalão, considerando-se quatro características: tempo insuficiente no cargo, vínculo a outro órgão governamental, formação não específica na área educacional, seleção para o cargo sem concurso público. Notese que estes comentários não contêm juízos de valor quanto à competência ou não dos entrevistados; apenas apontam para uma deficiência na estrutura, à luz da literatura utilizada neste trabalho.

Com relação à formação continuada na $\mathrm{EaD}$, o gestor do MEC entrevistado constata que as atividades estão divididas entre vários órgãos, o que prejudica a construção de uma política nacional:

A formação continuada é toda dividida. Ela não está toda aqui, por isso que esse nome de formação continuada é até informal. Tem uma parte da formação continuada que está na CAPES, [...] um pedaço que está na SECADI, [...] e outro que está na SEB. Aqui na SEB também é dividido: saúde na escola e educação integral estão em outra diretoria; tem uma outra diretoria que não sei o nome que trabalha TV Escola e um curso do e-proinfo, e ai, a parte da formação continuada que é relativa à educação básica, sem ser esses aspectos, está aqui. Fácil, né? (Entrevistado MEC C, 2012). 
Nota-se que políticas públicas, muitas vezes, são movidas pela pressa política, em busca de estatísticas e não raro acompanhadas da falta de planejamento coerente e que abarque todas as necessidades da área, fato esse que denota, novamente, outra preocupação no desenvolvimento das políticas de formação continuada, sejam elas presenciais ou a distância.

Com relação ao acesso a documentos relativos à $\mathrm{EaD}$ do $\mathrm{MEC}$, recebemos a informação de que não estavam disponíveis para consulta física, mas, tão somente, no site. Assim, não tivemos acesso a eles por falta de localização no site, visto que nesse espaço as informações estão, muitas vezes, desatualizadas, carentes de historicidade e progressão das ações.

À luz do conceito de autonomia inserida (EVANS, 1993; 2004), não conseguimos visualizar, nem nas entrevistas e nem no site do MEC, mecanismos que pudessem promovê-la nas ações de $\mathrm{EaD}$, mas percebemos um mecanismo que atua tanto para a formação presencial quanto a distância, no que se refere ao Fórum Estadual Permanente de Apoio à Formação Docente. Criado em 2009 por meio da Portaria $n^{\circ} 883$, esse Fórum tem como uma das principais funções definir prioridades e metas do programa em cada estado, elaborando e acompanhando a execução de um plano estratégico. É um Fórum institucionalizado e necessário para a participação no Plano Nacional de Formação dos Professores da Educação Básica.

O Fórum tem de fazer o planejamento estratégico do estado, é ele que recebe as demandas de todos os municipios, chama as universidades para ver que cursos elas querem oferecer e faz essa organização de demanda e oferta. Então, ele vai gerar um planejamento estratégico que será examinado pelo comitê gestor do MEC. [...]. A gente sabe que alguns Fóruns não funcionam muito bem, mas outros funcionam otimamente bem. (Entrevistado MEC C, 2012).

O entrevistado manifestou que nem todos os Fóruns têm desenvolvido as reuniões e atendido às necessidades. O entrevistado Fórum UAB A (2012) também confirma isso:

Esses cursos da SECADI a distância pedem a passagem pelo Fórum para a aprovação do curso. Mas esse Fórum não tem acontecido, não tem sido atuante. (Entrevistado FÓRUM UAB A, 2012).

Nesse estudo, o Fórum é visto como mecanismo de autonomia inserida de repercussão nacional. Entretanto, além da falta de organização nos estados, existe ainda o empecilho mencionado pelo entrevistado do MEC: 
Do ano passado pra cá, o MEC reorganizou essa participação nos Fóruns, designando novas pessoas. Até então, apenas três representantes do Ministério participavam de todos os Fóruns e, imagine, passamos esse número para 14. Estamos, portanto, animando esses Fóruns, e devemos fazer um encontro deles aqui em Brasilia, ainda esse ano. É o Fórum que deve fazer essa articulação. (Entrevistado MEC C, 2012).

Enfrentar o tema parecia ser uma preocupação do gestor, inclusive apontando uma possível alternativa para reverter o quadro.

Entrando agora nos domínios do Inep, este foi transformado em autarquia federal vinculado ao MEC pela atual Lei n. 10.269, de 29 de agosto de 2001 e tem por finalidade, principalmente, promover estudos, pesquisas e avaliações sobre o sistema educacional brasileiro.

Em 2012, a estrutura organizacional do INEP era definida com base no decreto $\mathrm{n}^{\mathrm{o}}$ 6.317, de 20 de dezembro de 2007. Como não existia nenhuma diretoria ou coordenação específica para atuação tendo como foco a $\mathrm{EaD}$, foram selecionados os entrevistados de acordo com as ações empreendidas na Educação Superior. Assim, foram entrevistados os atores: da Diretoria de Avaliação do Ensino Superior, da Coordenação do Censo da Educação Superior, da Coordenação do Enade, sendo que, dos três entrevistados, dois eram concursados do INEP e um era cedido de uma universidade pública.

O primeiro gestor entrevistado possuía graduação em Pedagogia, mestrado em engenharia de produção, e estava cursando doutorado em educação. Não era concursado do INEP e, sim, servidor de uma universidade pública cedido para o órgão. O segundo gestor entrevistado possuía graduação em Ciências Sociais, era concursado do INEP, no cargo de pesquisador tecnologista desde 2008. Estava desde maio de 2012 na função de gestor, ou seja, menos de um ano quando foi realizada a coleta de dados. O terceiro entrevistado tinha formação em Economia, com especialização em Planejamento, concursado do INEP como pesquisador tecnologista e estava desde 2010 no cargo em que ocupava, ou seja, há dois anos quando da coleta de dados.

Como pode ser inferido, os cargos do INEP eram ocupados, em sua maioria, por meio de concurso público, o que demonstra encaminhamento para uma organização burocrática nos moldes propostos por Evans (1995; 2004). Entretanto, apesar de ter um maior número de pessoas em cargos de alto escalão vinculadas ao órgão, o tempo de permanência nesses cargos era inferior a dois anos.

Com relação aos aspectos que envolvem a autonomia inserida, o entrevistado INEP C (2012) relatou: 
É uma troca real, não é só ouvir. Está havendo uma alteração de conceito do $C P C^{6}$, da construção do $C P C$, por causa do Enade sem ingressante. Nós vamos autorizar a nota do Enem e para calcular o IDD'. Alguns cursos não tem estudantes que fižeram o Enem, então tem que fažer outra divisão de pesos, das variáveis. A diretoria montou comissões para discutir isso, não foi uma coisa interna decidida aqui no gabinete, foi feita com várias comissões, com especialista em construção de indicadores e conceitos, e ela fez reuniões com as federais, fez reuniões com a $A B M E S^{8}$, pois a Diretoria ouve e considera o que o grupo coloca. [...] Então, é uma coisa que a gente ouve e leva, e se for possivel mudar a gente muda sim, a gente melhora. [...] A Diretoria não toma decisões sożinha, ela cria comissões com especialistas de diversos interesses, assim, um aqui tem um interesse, outro aqui tem outro, e depois a gente junta isso tudo. (Entrevistado INEP C, 2012)

O excerto do entrevistado INEP C demonstra que o uso de comissões abertas, não apenas as compostas de profissionais do órgão, agrega valor e pode ser considerado um mecanismo de autonomia inserida. Não se pode afirmar que ocorre sempre ou que seja recorrente, mas assim é na visão do entrevistado e do exemplo abordado.

A Comissão Nacional de Avaliação da Educação Superior (CONAES) é o órgão colegiado de coordenação e supervisão do Sistema Nacional de Avaliação da Educação Superior (SINAES), instituído pela Lei no 10.861, de 14 de abril de 2004.

Consideramos nesta pesquisa a CONAES como um mecanismo de autonomia inserida, por conferir atribuições aos representantes da comunidade para tomadas de decisão na área da avaliação da Educação Superior no Brasil. Mas, ao analisarmos a quantidade de representantes, num país continental como o nosso, e que atua na formação de profissionais de diversas grandes áreas, ter um representante apenas para os discentes, docentes e técnico-administrativos das IES pode transformar-se mais num mecanismo de exclusão dessa oportunidade de lidar com as necessidades e anseios sociais que de inclusão nela.

A primeira comissão da CONAES data de 2004. O presidente estava no cargo há um ano e a rotatividade na presidência mostrava-se alta, conforme dados do site da CONAES (2012) resumidos no Quadro 1.

\footnotetext{
6 Conceito Preliminar de Curso.

7 Diferença entre o desempenho médio do concluinte de um curso e o desempenho médio estimado para os concluintes desse mesmo curso 


\section{Quadro 1 - Períodos no cargo por mandato CONAES.}

Fonte: Lima (2013)

\begin{tabular}{|c|c|}
\hline MANDATO & PERÍODO NO CARGO \\
\hline Primeiro presidente & 3 anos - 2004 a 2006 \\
\hline Segundo presidente & 3 anos- 2007 a 2009 \\
\hline Terceiro presidente & 1 ano - 2010 \\
\hline Quarto presidente & 1 ano - 2011 \\
\hline Quinto presidente & 1 ano - 2012 \\
\hline
\end{tabular}

$\mathrm{Na}$ CONAES foram realizadas duas entrevistas. O primeiro entrevistado era formado em Física, com mestrado e doutorado na mesma área. Foi convidado a fazer parte da CONAES pelo Ministro da Educação. O Segundo entrevistado era formado em Química, licenciado em Química e Pedagogia, mestre em História Social e doutor em Educação, sendo indicado ao cargo.

Quando questionamos sobre a relação com a comunidade na busca de coleta de indícios de mecanismos de autonomia inserida, fomos informados que a CONAES vinha fazendo uso das audiências públicas como mecanismo de escuta das universidades particulares, públicas e das associações. A maneira com que as audiências públicas eram utilizadas pode transformar-se em mecanismos de autonomia inserida do órgão colegiado à medida que abriam para discussão os diversos encaminhamentos, mas com autonomia para a tomada de decisão final, se realmente utilizada para isso. Observou-se que a CONAES se estruturava de maneira a permitir um trabalho de forma colegiada, com membros limitados e indicados pelo Ministro da Educação.

\section{CAPACIDADE BUROCRÁTICA: CAPACITAÇÃO E PLANO DE CARREIRA}

Por ser o Brasil um Estado intermediário na classificação de Evans (1995), a análise das condições de oferta e políticas voltadas a plano de carreira e de capacitação auxilia na compreensão da capacidade do Estado de implementar as políticas de educação superior a distância.

De acordo com Rauch e Evans (2000), a estabilidade na atividade do serviço público proporcionada pela promoção interna tende a permitir a formação de laços mais fortes entre os funcionários, melhora a comunicação, e, por conseguinte, a eficácia. Isso pode ser percebido em mecanismos como planos de carreira e de capacitação. 
Assim, procuramos levantar, por meio das entrevistas, como ocorriam estes dois mecanismos, relacionando-as com a regulamentação encontrada a respeito. Questionamos sobre a formação oferecida aos entrevistados e aos executores da política de $\mathrm{EaD}$, ou seja, aos que estão na ponta. A formação continuada e a capacitação profissional, além de fazerem parte de um dos critérios de capacidade burocrática do Estado, foram regulamentadas pelo Decreto $\mathrm{n}$. 5.707, de 23 de fevereiro de 2006, o qual instituiu a Política e as Diretrizes para o Desenvolvimento de Pessoal da administração pública federal direta, autárquica e fundacional.

Os entrevistados da CAPES não apresentaram contradições em suas respostas e observaram que a instituição possuía um programa de formação continuada para os servidores, com cursos mais amplos e gerais, que atendiam a todos que ali trabalhavam, como informática avançada. Pelo que apresentaram, existia uma grade de cursos, não disponibilizada para nossa pesquisa. Entendemos que, caso um servidor solicitasse um determinado curso, isso poderia ser viabilizado de acordo com a demanda, a partir de um pacote, e, com a autorização do superior imediato, a CAPES apoiaria com recursos financeiros.

Com relação à capacitação de quem implementa a política pública de $\mathrm{EaD}$, foram unânimes em dizer que não se oferecia qualquer tipo de formação, mas se fomentavam propostas que eram avaliadas por pares das IES para a oferta de formação em EaD para os executores. Isto parece uma incoerência, já que os executores elaboram a formação para atuação na execução e implementação da política, mas, ao mesmo tempo, favorece as instituições que já possuem experiência e profissionais capacitados, ainda que as capacitações permaneçam limitadas à região em que são ofertadas.

O entrevistado CAPES E (2012) defendia a indução para um compartilhamento maior de cursos e capacitações em EaD para os executores, e, assim, complementava:

\begin{abstract}
$\mathrm{Na}$ verdade, não existe esse curso da CAPES, mas este ano nós já estamos comecando uma linha de indução, de formação em EaD, porque sentimos que existe muita carência nas nossas instituições, no próprio país. Começamos então, agora, a montar o que a gente está chamando de um curso nacional modular e sobre educação a distância. Só que é assim: como já temos muita coisa estabelecida, não precisamos partir do zero, vamos conhecer o que existe, pois devem existir muitos materiais, muita coisa boa. (Entrevistado CAPES E, 2012).
\end{abstract}

A fala do entrevistado CAPES E (2012) denota uma preocupação em construir um curso de âmbito nacional e aponta para outra: nota-se um desconhecimento do que é ofertado pelas Instituições de Ensino Superior Públicas com o fomento que é dado pela própria CAPES, apesar de esse mesmo entrevistado defender a importância da formação para atuar na EaD: 
O PAC, que já vem se desenvolvendo, é essencial, porque dá as condições para aquela instituição que está ofertando cursos também capacitar os seus tutores, os seus autores. A UAB foi muito feliz ao pensar que, na verdade, não é só fomentar, não é só faz̧er o fomento, mas é também dar as condições para que esse fomento também inclua a formação em $\mathrm{EaD}$ para preparação das equipes que vão estar desenvolvendo os cursos. Então, não é só a bolsa para o professor, para o tutor, não; a formação é importantíssima. Você imagina um tutor que não épreparado para atuar na educação a distância, eu não imagino, pois é fundamental, assim como eu não imagino um professor atuando na EaD sem ter uma formação. Eu acho que o PAC, que é o plano anual de capacitação continuada em EaD, é o que ele far: (Entrevistado CAPES E, 2012).

Com relação ao plano de carreira, conforme o Entrevistado CAPES E (2012), não havia um que lhe parecesse específico. Seguiam a Lei n. 8.691, de 28 de julho de 1993 (BRASIL, 1993), que dispõe sobre o plano de carreira para a área de ciência e tecnologia da administração federal direta, das autarquias e das fundações federais.

A legislação atualizada sobre o Plano de Carreira da CAPES e dos demais servidores públicos federais pode ser encontrada no site de legislação da Presidência da República: http:/ / wnw planalto.gov.br/legislacao. (Resposta E-SIC).

A CAPES não tem um plano de carreira próprio. Na verdade, os servidores da CAPES fazem parte da carreira de ciência e tecnologia, assim como os de outros órgãos/ entidades. (Entrevistado CAPES D, 2012).

Pelo ano em que foi regulamentada a referida Lei, podemos ver que o plano de carreira da CAPES é o mais antigo, se comparado aos outros órgãos.

Os entrevistados do Fórum de Coordenadores UAB corroboraram as colocações dos entrevistados da CAPES quando afirmaram que nunca receberam curso de capacitação ou formação para atuarem na função, e vários deles assumiram a função sem ter trabalhado antes com $\mathrm{EaD}$ ou participado de curso $\mathrm{UAB}$.

As entrevistas salientaram a não exigência de formação em EaD para ocupar o cargo de coordenador de EaD nas instituições de origem, a alta rotatividade do cargo nas universidades, e falta de formação ou preparação para o cargo. Essas evidências limitam a atuação e geram uma série de atrasos na continuidade das ações, justamente por falta de conhecimento e formação. Com relação ao plano de carreira, não se aplica ao Fórum, visto que ele funciona como órgão colegiado.

Com relação ao plano de carreira do MEC, solicitamos essa informação no site do Serviço de Informação ao Cidadão, obtendo a seguinte resposta:

O Ministério da Educaşão não possui um plano de carreira específico; os cargos efetivos do quadro do MEC são integrantes do Plano Geral de Cargos do Poder Executivo - PGPE, estruturado pela Lei ñ 11.357, de 2006. Assim, as disposições acerca da carreira estão contidas 
na referida norma. Além da Lei que estrutura a carreira, bá o Decreto no 7.133 de 2011, que regulamenta os critérios e os procedimentos gerais a serem observados para a realização das avaliaçoes de desempenho individual e institucional, para fins de pagamento da GDPGPE gratificaşão específica da carreira. Os critérios específicos, estabelecidos no âmbito deste Ministério, estão disciplinados pela Portaria MEC ñ 1.245, de 8 de outubro de 2010. (Resposta E-SIC, 2012).

A falta de plano de carreira específico para os servidores do MEC fazia com que a rotatividade fosse grande, diminuindo a capacidade do Estado, além de não proporcionar incentivos para a busca de formação continuada, especialização e dedicação exclusiva ao trabalho desenvolvido, conforme descreve o entrevistado:

Cursos sofrem mudanças radicais em sua estrutura, inclusive na qualidade da oferta, principalmente porque, no âmbito do MEC, [...] falta servidor do quadro concursado, eles são terceirizados. [...] Há quase quinze anos e ainda estão os não concursados, desde o governo FHC. (Entrevistado SEED B, 2012).

Por fim, com relação ao MEC, o entrevistado do INEP A (2012) demonstrava a mesma visão sobre a perda que o Ministério sofre por não ter um plano de carreira mais delimitado:

O que acontece: os cargos disponiveis do MEC, os salários são muito baixos, o plano de carreira é muito ruim, ao contrário do INEP, que tem plano de carreira e pode contratar um pesquisador, um professor ou um doutor que tenha mais condição de fazer determinado trabalho. No MEC, não. (Entrevistado INEP A, 2012).

No INEP, um entrevistado disse que a autarquia fez seu primeiro plano de capacitação anual em 2012, apesar de já oferecer apoio financeiro a quem o solicita para formação continuada. Mas, como política do órgão, o início se deu apenas em 2012, apesar de a Lei exigir esse plano desde 2006. Com relação à existência de programa de formação continuada ou capacitação, três entrevistados responderam que:

O INEP tem, como toda a administração pública agora exige, até por determinação do Ministério do Planejamento, todo órgão do executivo federal tem que ter um plano de capacitação anual. $O$ INEP fez o primeiro agora em 2012, mas foi uma primeira experiência. (Entrevistado INEP $B, 2012)$.

Tem. Nós aqui, no INEP, temos buscado constituir isso, quer dizer, chamamos professores. $\mathrm{Na}$ semana passada teve uma equipe de EaD aqui, discutindo com nossos técnicos sobre as propostas. [...]. Em 2010 nós iniciamos um programa de formação entre nossos técnicos e eu solicitei que cada um deles acompanhasse uma avaliação pública, privada, junto com os avaliadores, porque se você orienta a avaliação, você tem de saber como é que é essa estrutura. (Entrevistado INEP A, 2012). 
Tem um programa do INEP, pelo menos eu recebi um documento solicitando uma previsão com a coordenadora de cursos para a equipe, do que seria necessário. [...] Eles abriram uma turma de mestrado, em convênio com a Federal de Juiz de Fora, e temos quatro pessoas da Diretoria fazendo. Agora abriram outra turma num convênio, em parceria com a Federal de Santa Catarina. Também temos mais três pessoas (Entrevistado INEP C, 2012).

Ao realizar uma busca pela Internet, encontramos, com data de 14 de outubro de 2012, o Edital n ${ }^{\circ}$ 2012-025-01 para seleção de consultor em desenvolvimento institucional para o INEP, com o objetivo de realizar um estudo exploratório e analítico das demandas de capacitação nas áreas meio e finalísticas do Instituto, e, ainda, elaborar uma proposta de capacitação para o quadro de seus servidores. Conforme a resposta do Entrevistado INEP B (2012), percebemos que uma forma de lidar com as dificuldades que ocorreram em 2012 para o planejamento dessa ação em 2013 foi recorrer a um consultor especialista na área.

Apesar de o plano de carreira do INEP ser recente no momento em que se realizou a pesquisa, vimos o esforço e a relevância de ter sido implementado, ainda que se mantenham profissionais não concursados (em número reduzido), no quadro.

$\mathrm{Na}$ CONAES, os entrevistados disseram que nunca receberam capacitação ou formação para exercer a função de membro:

Formalmente, não. Tenbo atuado na discussão e na elaboração da política educacional desde o período que cursava a graduação na UNICAMP'. Fui militante do movimento estudantil e do movimento sindical por muitos anos. Quando fui indicado para exercer essa função pela Confederação Nacional dos Trabalhadores em Estabelecimentos de Ensino - CONTEE - fui orientado sobre as dificuldades e os desafios que teria pela frente. Além disso, o exercício da função exige muita leitura e estudo sobre o tema. (Entrevistado CONAES B, 2012).

Não existe na CONAES, por ser um órgão colegiado, plano de carreira, pois seus membros são de outros órgãos e instâncias, com o vínculo em seus órgãos de origem, assim como no Fórum ${ }^{10}$.

\section{CONSIDERAÇÕES FINAIS}

A análise da organização burocrática do Estado para gerir as políticas públicas de $\mathrm{EaD}$, permitiu-nos algumas considerações que bem poderiam servir de alerta. Como observa Evans (2004), a falta de burocracia pode ser uma das causas da ineficácia do Estado.

$9 \quad$ Universidade Estadual de Campinas.

10 Dentro do contexto desta pesquisa não pretendemos comparar os órgãos pesquisados, pois cada um apresenta especificidades, com diferenças cabíveis em torno de seus objetivos e estrutura. 
Assim, verificamos que dentre os órgãos que em 2012 exerciam atividades relativas à EaD, a CAPES contava com a Diretoria de Educação a Distância e três Coordenações-Gerais; e o MEC, por meio da SERES, com duas Coordenações-Gerais. Considerando a expansão da modalidade no Brasil desde a sua regulamentação referente a matrículas da $\mathrm{EaD}$ e a quantidade de pessoas dedicadas a estes setores, inferimos que há insuficiência de pessoal e setores para uma atuação efetiva do Estado na área.

Conforme pontua Evans (2004), ao analisar a burocracia brasileira definindo o Estado brasileiro como intermediário, confirmamos algumas de suas características também na área da educação e nos cargos ocupados especificamente para a $\mathrm{EaD}$, em que se observou a predominância da carreira em staccato, pontuada pelos ritmos de mudança de governo em curto espaço de tempo (menos de quatro ou cinco anos), tendo sido indicados para o cargo profissionais de fora do próprio órgão, acarretando limitação para o desenvolvimento de compromissos a longo prazo. A ocupação dos cargos de alto escalão, na maioria dos casos, foi feita por profissionais vinculados a outros órgãos de origem e não àqueles em que atuam (verificamos, inclusive, a presença de atores que ocupavam o cargo de forma comissionada, sem vinculação com o serviço público). As carreiras se caracterizavam pela rotação rápida, o que impossibilita a aquisição gradual de conhecimentos e habilidades relevantes. Nesse conjunto de argumentos encaixava-se também a situação dos planos de carreira nos órgãos pesquisados.

Como facilitadores do desenvolvimento das capacidades estatais, podemos destacar: na CAPES, os gestores de alto escalão tinham experiência na área, inclusive alguns com formação específica para EaD; a manutenção do Fórum de Coordenadores UAB ao longo das duas gestões da DED/CAPES e o fato de todos os Coordenadores UAB das IES participantes fazerem parte do Fórum de Coordenadores UAB, contribuindo nas reflexões e encaminhamentos; além disso, o INEP mantinha, em sua maioria, funcionários concursados para suas funções.

Alguns entraves ficaram evidentes. No que se refere à CAPES, apesar da nomenclatura da DED ser voltada para o atendimento geral da EaD, o foco de suas atribuições estava na UAB e na formação de professores, e não na $\mathrm{EaD}$ em âmbito nacional. O cargo nas IES para o Coordenador UAB tinha seus critérios definidos pela Resolução CD/FNDE n 26, de 5 de junho de 2009, a qual não prevê a experiência anterior na área da $\mathrm{EaD}$. O Estado carecia de setor ou órgão que pudesse definir uma política pública de $\mathrm{EaD}$ que abarcasse o setor público e o privado.

Percebemos, pelos dados apresentados, que o Estado estava num processo embrionário, tanto em termos de planos de carreira quanto de capacitação dos seus 
atores na área da $\mathrm{EaD}$. Na maioria dos casos os órgãos apoiavam financeiramente os funcionários para cursos de pós-graduação de acordo com a demanda. Mas tal situação torna-se um entrave na medida em que não se apresentam os requisitos e critérios para essa formação. A falta de investimento do Estado na formação dos gestores em EaD mantém a deficiência de conhecimento sobre as especificidades da modalidade. O MEC não possuía plano de carreira específico para seus servidores, a CAPES também não possuía plano específico, estando inserida no plano de carreira da área de ciência e tecnologia da administração federal direta. O INEP foi regulamentado apenas em 2006, carecendo, ainda, de muitas discussões, conforme entrevistados.

A arquitetura institucional no que se refere a ações de autonomia inserida não chegava a limitar a capacidade do Estado, mas sua condição incipiente não permitia aportar contribuição significativa no sentido de fortalecê-la. O uso de Fóruns regulamentados por área e ação específica e das audiências públicas, demonstrou ser um mecanismo de autonomia inserida, desde que bem coordenados, induzidos e representados. O Fórum de Coordenadores UAB pôde ser visto como um mecanismo de autonomia inserida, pois, além de ser um canal institucionalizado como política de governo, contribuía para os encaminhamentos dos problemas e necessidades a serem revistos e adaptados. O Fórum Estadual Permanente de Apoio à Formação Docente, criado pela Portaria do MEC n. 883 de 2009 (BRASIL, 2009a), poderia ser uma ótima rede externa para a autonomia inserida por ser um Fórum regulamentado (EVANS, 2004) para definir prioridades e metas em cada estado. Entretanto, os dados mostraram que não estavam funcionando bem em todos os estados.

Salientamos, também, que a multiplicidade de atores que envolvem a arquitetura institucional de EaD pública demonstrou o desenvolvimento de ações em âmbitos independentes que acabaram por levar à sua fragmentação, demonstrando a falta de um eixo comum que pudesse ser o tradutor das políticas de $\mathrm{EaD}$ com os interesses comuns e de forma cooperada.

A falta de conhecimento específico/formação/capacitação e experiência, que levam à percepção das especificidades da $\mathrm{EaD}$, mostrou-se, também, uma questão relevante, não apenas para a gestão da $\mathrm{EaD}$, mas para a construção de mecanismos de autonomia inserida e para o aproveitamento do potencial sinérgico existente entre os órgãos pesquisados para a construção da visão, concepção e realidade da $\mathrm{EaD}$ no país.

Essas considerações se tornam, a nosso ver, uma necessidade prioritária para os próximos encaminhamentos ou formação de novas agendas para a EaD, 
pois os órgãos que lidam com seu acompanhamento, gestão, regulação, supervisão e avaliação precisam ser consoantes com suas especificidades e proporcionar atividades cooperadas para sua implementação.

\section{REFERÊNCIAS}

BRASIL. INEP. Censo da Educação Superior: Sinopse Estatística 2002 e 2016. Disponível em: < http://inep.gov.br/sinopses-estatisticas-da-educacaosuperior>. Acesso em: 10 jan. 2018.

BRASIL. Decreto $\mathbf{n}^{\mathbf{0}}$. 9.057, de 25 de maio de 2017. Regulamenta a o art. 80 da LDB 9.394/1996, que estabelece as diretrizes e bases da educação nacional. Disponível em: < http://www.planalto.gov.br/ccivil_03/_ato2015-2018/2017/ decreto/D9057.htm>. Acesso em: 10 jan. 2018.

BRASIL. CAPES. Portaria $\mathbf{n}^{\mathbf{0}} \mathbf{7 9}$ e 170. Dispõe sobre Fórum Coordenadores UAB. Disponível em: < http://www.capes.gov.br/component/content/ article/53-servicos/2340-portarias>. Acesso em: 08 fev. 2012.

BRASIL. Decreto n. 7.692, de 2 de março de 2012. Aprova estatuto e quadro da Capes. Disponível em: < http:/ /www2.camara.leg.br/legin/fed/decret/2012/ decreto-7692-2-marco-2012-612509-norma-pe.html>. Acesso em: 10 mar. 2013.

BRASIL. Portaria n. 883, de 16 de setembro de 2009a. Institui o Fórum FEPAFD. Disponível em: <https://www.capes.gov.br/images/stories/ download/legislacao/Portaria-883-DiretrizesForunsEstaduais.pdf $>$. Acesso em: 10 mar. 2012.

BRASIL. Resolução/FNDE n. 26, de 05 de junho de 2009b. Disponível em: < http://www.fnde.gov.br>. Acesso em: 08 fev. 2012.

BRASIL. Decreto n. 5.800, de 8 de junho de 2006. Dispõe sobre o Sistema Universidade Aberta do Brasil. Disponível em: < http://www.planalto.gov.br/ ccivil_03/_ato2004-2006/2006/decreto/d5800.htm>. Acesso em: 10 mar. 2017.

BRASIL. Decreto n. 5.707, de 23 de fevereiro de 2006. Institui a Política e as Diretrizes para o Desenvolvimento e administração pública federal direta. Disponível em: <http://www.planalto.gov.br/ccivil_03/_Ato2004-2006/2006/ Decreto/D5707.htm>. Acesso em 10 mar. 2013. 
BRASIL. Decreto n. 5.262, de 3 de novembro de 2004a. Designa membros Conaes. Disponível em: < http://www2.camara.leg.br/legin/fed/decret/2004/ decreto-5262-3-novembro-2004-534441-publicacaooriginal-20179-pe.html>. Acesso em: 19 mar. 2013.

BRASIL. Decreto n. 5.176, de 10 de agosto de 2004b. Regulamenta a carreira de especialista em políticas públicas. Disponível em: <http://www.planalto.gov.br/ ccivil_03/_ato2004-2006/2004/decreto/d5176.htm>. Acesso em: 19 mar. 2013.

BRASIL. Lei n. 10.861, de 14 de abril de 2004. Institui o Sistema Nacional de Avaliação do Ensino Superior. Diário Oficial de 15 de abril de 2004c.

BRASIL. Lei n. 10.269, de 29 de agosto de 2001. Denominação ao INEP. Disponível em: < http://www2.camara.leg.br/legin/fed/lei/2001/lei-10269-29agosto-2001-391813-publicacaooriginal-1-pl.html>. Acesso em: 10 mar. 2013.

BRASIL. Lei $\mathbf{n}^{\mathbf{0}} \mathbf{9 . 3 9 4}$, de 20 de dezembro de 1996. Estabelece as Diretrizes e Bases da educação Nacional. Disponível em: < http://www.planalto.gov.br/ ccivil_03/leis/19394.htm>. Acesso em: 08 jan. 2018.

BRASIL. Lei n. 8.691, de 28 de julho de 1993. Dispõe sobre Plano de Carreiras. Disponível em: < http://www2.camara.leg.br/legin/fed/lei/1993/lei-8691-28julho-1993-372206-norma-pl.html>. Acesso em: 10 mar. 2013.

BRASIL. Lei $\mathbf{n}^{\mathbf{0}} \mathbf{8 . 0 2 8}$, de 12 de abril de 1990. Dispõe sobre a organização da Presidência da República e dos Ministérios, e dá outras providências. Disponível em: < http://www2.camara.leg.br/legin/fed/lei/1990/lei-8028-12-abril-1990372178-norma-pl.html>. Acesso em: 02 mar. 2018.

BRASIL. Lei n. 7.834, de 6 de outubro de 1980. Cria a carreira e os respectivos cargos de especialistas em políticas públicas e gestão governamental. Disponível em: < http://www.planalto.gov.br/ccivil_03/leis/L7834.htm>. Acesso em: 19 mar. 201

COSTA, L. A. Insulamento burocrático, autonomia do estado e inserção social: um estudo do Ministério da Saúde na coordenação nacional do SUS. 2011. 166 f. Tese (Doutorado em Sociologia) - Universidade Federal de Minas Gerais. Belo Horizonte, 2011. 
COSTA, L. A.; NEVES, J. A. B. Burocracia e inserção social: um estudo sobre o Ministério da Saúde na gestão do Sistema Único de Saúde (SUS). Saúde Soc. , v. 22, n. 4, 2013. Disponível em: < http://www.scielo.br/pdf/sausoc/v22n4/14. pdf>. Acesso em: 10 fev. 2018.

EVANS, P. Autonomia e parceria: estados e transformação industrial. Rio de Janeiro: Ed. UFRJ, 2004.

. Embedded autonomy: states and industrial transformation. Princeton, NJ: Princeton University Press, 1995.

. O Estado como problema e solução. Revista Lua Nova, São Paulo, n. 28 e 29, p. 107-156, 1993.

GRINDLE, Merilee Serrill. Challenging the State: crisis and innovation in Latin America and Africa. Cambridge: Cambridge University Press, 1996.

LIMA, Daniela da Costa Britto Pereira. Políticas públicas de EaD no ensino superior: uma análise a partir das capacidades do Estado. Tese (Doutorado em Políticas Públicas, Estratégias e Desenvolvimento) - Rio de Janeiro, UFRJ, 2013.

MORAES, Raquel de Almeida. O Proformação e seu modelo de educação a distância. Revista HISTEDBR On-line, Campinas, n. 44, p. 262-274, dez. 2011. Disponível em: < http://www.fae.unicamp.br/revista/index.php/histedbr/ article/view/3144/2816>. Acesso em: 12 nov. 2012.

RAUCH, James E.; EVANS, Peter B. Bureaucratic structure and bureaucratic performance in less developed countries. Journal of Public Economics., v. 75, p. 49-71, 2000. Disponível em: < http://www.sciencedirect.com/science/article/ B6V76-3XVPG5W-3/2/cc4bf41c94f40ad95f544a60f784dcb3>. Acesso em 10 mar. 2013.

DANIELA DA COSTA BRITTO PEREIRA LIMA é Doutora em Políticas Públicas, Estratégias e Desenvolvimento pela UFRJ. Professora do Programa de Pós-Graduação em Educação - FE/UFG. Líder do GEaD - Grupo de Estudos e Pesquisa em Tecnologias e Educação a Distância/CNPq. E-mail: professoradanielalima@gmail.com 
MÔNICA DESIDERIO possui Pós-Doutorado em Políticas Públicas de Inovação em Saúde - CDTS/Fiocruz (2013), Doutorado em Ciências Sociais pela UFRRJ (2008). Head dos MBAs da BSP - Business School São Paulo. Professora convidada (pós-graduação lato sensu) da FGV Management, Unifor, IE/UFRJ. E-mail: monica.desiderio@prof.bsp.edu.br

Recebido em fevereiro de 2018 Aprovado em abril de 2018 